\title{
ANALYZING SPATIOTEMPORAL PATTERNS OF EXTREME PRECIPITATION EVENTS IN SOUTHEASTERN ANATOLIA
}

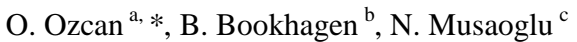 \\ ${ }^{\text {a }}$ ITU, Application and Research Center for Satellite Communications and Remote Sensing, Istanbul, TR \\ - orkan@cscrs.itu.edu.tr

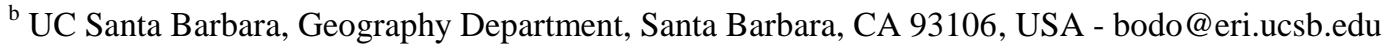 \\ c ITU, Department of Geomatics Engineering, 34469 Maslak, Istanbul, TR - musaoglune@itu.edu.tr
}

KEY WORDS: TRMM, Extreme events, GEV, Shape parameter, Precipitation, South-eastern Anatolia

\begin{abstract}
:
Extreme environmental events, such as floods, droughts, rainstorms, and strong winds have severe consequences for human society. Changes in extreme weather and climate events have significant impacts and are among the most serious challenges to society in coping with a changing climate. The cost of damage caused by extreme climate events is rising all over the world. The European Environment Agency (EEA) report ("Climate Change, Impacts and Vulnerabilities in Europe 2012") stated that the cost of damage had increased from $€ 9$ billion in the 1980 s to $€ 13$ billions in the 2000s. In the United States, the National Oceanic and Atmospheric Administration (NOAA) reported that \$188 billion in damage was caused by the severe weather events in 2011 and 2012 . Understanding and identifying hydrometeorologic extreme events and their changes through time are key in sustaining agriculture and socio-economic development. Planning for weather-related emergencies, agricultural and reservoir management and insurance risk calculations, all rely on knowledge of the frequency of these extreme events. The assessment of extreme precipitation is an important problem in hydrologic risk analysis and design. Erosion and removal of the fertile soil layer through hydroclimatic extreme events is also a serious problem in semi-arid to arid regions, especially in mediterranean climates. Accurate measurements of precipitation on a variety of space and time scales are important to climate scientists and decision makers, including hydrologists, agriculturalists and emergency managers. The historical record of precipitation observations is limited mostly to land areas where rain gauges can be deployed, and measurements from those instruments are sparse over large and meteorologically important regions of the Turkey, such as over the Southeastern Anatolia Region. While rain gauge measurements are often used to tune hydrologic models, they are limited by their spatial coverage. Remote sensing techniques using spaceborne sensors provide an excellent complement to continuous monitoring of rain events both spatially and temporally. In this study we compare ground-station data with Tropical Rainfall Measurement Mission (TRMM) products at the 3-hour time scale to evaluate satellite rain estimates for agricultural and hydrological applications in Turkey. The remote sensing dataset TRMM product 3B42 has been validated with daily rain gauge measurements in order to characterize rainfall variability in the Southeastern Anatolia region. The precipitation retrievals from the TRMM satellite were compared with data from 7 surface rain gauges within the period of 1998 - 2012. Spatiotemporal patterns through statistical analyses were identified by fitting Generalized Extreme Value (GEV) rainfall distribution to the rainfall time series, and the fitting results were analyzed focusing on the behaviour of the shape parameter. Spatial patterns and correlations of rainfall events across the study area were also analysed by the calculation of the $90^{\text {th }}, 95^{\text {th }}$ and $99^{\text {th }}$ percentiles. Regional frequency relationship were developed using the chosen GEV distribution. The recurrence intervals for different years have been estimated using the GEV distribution and their spatial variability has been described. The recurrence intervals of large rainstorms have also been identified for the rain gauge stations with the related TRMM pixel time series and spatial patterns in the study area have been evaluated. Preliminary results indicate that there exist large discrepancies between rain gauge and TRMM data at mean rainfall values; however, least squares fits indicate reliable and quite linear correlation for the $90^{\text {th }}, 95^{\text {th }}, 99^{\text {th }}$ percentiles $\left(\mathrm{r}^{2}=0.70,0.77\right.$, and 0.75 respectively) and the annual maximum daily amount of precipitation $\left(\mathrm{r}^{2}=0.69\right)$. In other words, TRMM product $3 \mathrm{~B} 42$ can be used to assess first-order rainfall statistics and recurrence intervals, but rainfall magnitudes vary significantly from ground measurements.
\end{abstract}

\section{INTRODUCTION}

Spatiotemporal determination of increases in extreme events associated with both natural and human in nature are being observed in recent years all over the world (e.g., Zscheischler et al., 2013; Boers et al., 2013; Bookhagen, 2010; Kunkel et al. 1999). The interest in studying these extreme natural events is to alleviate their impact on humans, properties and sources of income such as agricultural fields. Extreme value theory has

\footnotetext{
* Corresponding author. Orkan Ozcan,

Application and Research Center for Satellite Communications and Remote Sensing. TR 34469 Maslak Istanbul,

Tel: +9021228568 13-128

Fax: +902122857167

E-mail: orkan@cscrs.itu.edu.tr
} 
long been applied to the study of these infrequent events and has been proven to be reliable in fitting models to historical data. The application of the extreme value theory has been used in diverse fields such as extensively in finance, environmental studies, economics, hydrology and climatology (e.g., Jenkinson, 1955; Embrechts et al., 1999). Extreme value distributions are the limiting distributions for the minimum or the maximum of a very large collection of random observations from the same arbitrary distribution. The knowledge of the variation of rainfall distribution in the hydrological cycle has a great importance in order to understand and to predict climate change and weather anomalies. Changes to the magnitude, character and spatial distribution of extreme rainfall may have serious social and economic implications. The Generalized Extreme Value (GEV) distribution is a family of continuous probability distributions developed within extreme value theory, which is a robust framework to analyse the tail behavior of distributions. Accurately estimating the tails of distributions is important for many risk-based applications. In environmental sciences, using specific thresholds such as the $90^{\text {th }}$ and $99^{\text {th }}$ percentiles of precipitation days or block maxima with GEV distribution approach to define extreme events can help decision makers determine the maximum level of risk against which they should protect (e.g., Kunkel et al., 1999).

Point measurements of precipitation serve as the primary data source for territorial analysis. However, even the best measurement of precipitation at one point is only representative of a limited area. The spatial and temporal variability of precipitation, along with surface characteristics and topography, are of paramount importance in understanding hydrological processes and land-atmosphere interactions over semi-arid and arid regions; yet rainfall remains one of the most difficult meteorological quantities to accurately measure. The spatiotemporal structure of precipitation greatly impacts land surface hydrological fluxes and states (e.g., Fekete et al., 2003; Gottschalck et al., 2005). In semi-arid to arid regions, landscape-shaping hydrologic events are often associated with extreme rainfall or flooding events (Bookhagen et al., 2005; Boers et al., 2013; Wulf et al., 2010; Wulf et al., 2012). Accurate measurements of precipitation over a wide range of both space and time scales are important to emergency managers, and decision makers with the intention of hydrometeorological and agricultural studies (Ebert et al., 2007). With the purpose to obtain more accurate estimates and a wider areal coverage of precipitation, satellite-based rainfall sensors with various spatial scales and resolutions have been deployed over the last decades. Rain gauges and other ground-based instruments are supplementary components of the satellite precipitation algorithm validation studies. They play a key role in both constructing and validating remote-sensing based rainfall estimates (Wolff et al., 2005). A unique platform used with the aim of characterizing tropical rainfall with remote sensors from space is the Tropical Rainfall Measuring Mission (TRMM), a joint project between NASA and the Japan Aerospace Exploration Agency (Wilheit, 2003). TRMM has provided rain radar and microwave radiometric combined data with a precipitation radar (PR) and a TRMM microwave imager (TMI) radiometer (Okamoto, 2003) since 1997. It measures the vertical distribution of precipitation in a band between latitudes $\pm 36^{\circ}$ and provides sampling of the complete diurnal cycle of rainfall. The current operational TRMM satellite combined with other satellite platforms, has enabled a wide range of precipitation products (Simpson et al., 1988; Kummerow et. al. 2000). Among these products, several studies suggest that the TRMM product $3 \mathrm{~B} 42$ surface-rainfall rate is comparable to the other surface observation (e.g., Huffman et al., 2007; Koo et al., 2009; Sapiano and Arkin, 2009), although the spatial scale of the rainfall data makes direct comparison to gauge data difficult (Bookhagen, 2010). We employ product 3B42, which merges TRMM satellite observation with other passive microwave radiometers that covers the latitudes latitudes $\pm 50^{\circ}$. Some global and regional validations have been reported for different satellite rain products (Xie and Arkin, 1995, Krajewski et al., 2000, Adler et al., 2001, Gebremichael et al., 2005). Also, a number of efforts have been made to compare TRMM products with other measurements (Adler et al., 2003; Nicholson et al., 2003; Bookhagen and Burbank, 2010; Bookhagen and Strecker, 2008), but these studies have usually been limited to comparisons on a monthly scale. In southeastern region of Turkey, where remotely sensed informations are arguably needed most, there has been very little validation work.

This study validates and compares remote sensing rainfall data from 15 years (1998-2012) of TRMM product 3B42 through comparison with 7 rainfall gauges (entire length 43 years, 19702012) in order to characterize rainfall variability in a part of semi-arid Southeastern Anatolia region. Daily rainfall amounts of extreme events have been determined by the calculation of the $90^{\text {th }}, 95^{\text {th }}$ and $99^{\text {th }}$ percentiles of the distribution for days with precipitation. The recurrence intervals for different years have been estimated using GEV distribution tion of annual maximum daily rainfall amounts and described how they vary among the rain gauge stations and the TRMM 3B42 grid cells. Besides, spatiotemporal patterns through statistical analyses were identified by fitting GEV rainfall distribution to the rainfall time series, and the fitting results were analyzed focusing on the behavior of the shape parameter for both rain gauge stations and the associated TRMM 3B42 grid cells.

\section{STUDY REGION AND DATA DESCRIPTION}

The study area in the Southeastern Anatolia region has the highest share of agricultural production in Turkey and displays major climatic features of the Eastern Mediterranean with strong continental influence. The long summers are hot and dry. The winters are cold with rainfall or snowfall. The annual average temperature is $18{ }^{\circ} \mathrm{C}$ and annual rainfall is around 350 $\mathrm{mm}$. There is significant seasonal variation in precipitation. Rainfall is highly seasonal, with more than $80 \%$ concentrated in the period November through March. The area receives almost no rain during the summer, at which time irrigation becomes crucial. The mean annual rainfall rates have been decreased significantly for the past 42 years, however summer rainfall series indicate a significant upward trend in this region. Increased rainfall amounts, with flush flooding, may have led to exist soil erosion more disastrous in this semi-arid region with sparse vegetation cover.

In recent years, some changes have been experienced in the climate in the region related to the dam construction and lake formation within the scope of the Southeastern Anatolia Project (GAP) (Fig. 1). The research region has a higher variability in crop yield and studies showed that the rainfall had a very significant impact on agricultural production in the region (Ozcan et al., 2012). Daily rainfall data for each station have been compared to the associated TRMM 3B42 grid cells (Huffman et al., 2007). The TRMM data come in a gridded format with a spatial resolution of $0.25^{\circ} \times 0.25^{\circ}(\sim 30 \mathrm{~km} \times 30$ $\mathrm{km})$ and a temporal resolution of 3 hours. For all spatiotemporal analyses, daily rainfall amounts have been used as integrated from the 3-h data. 


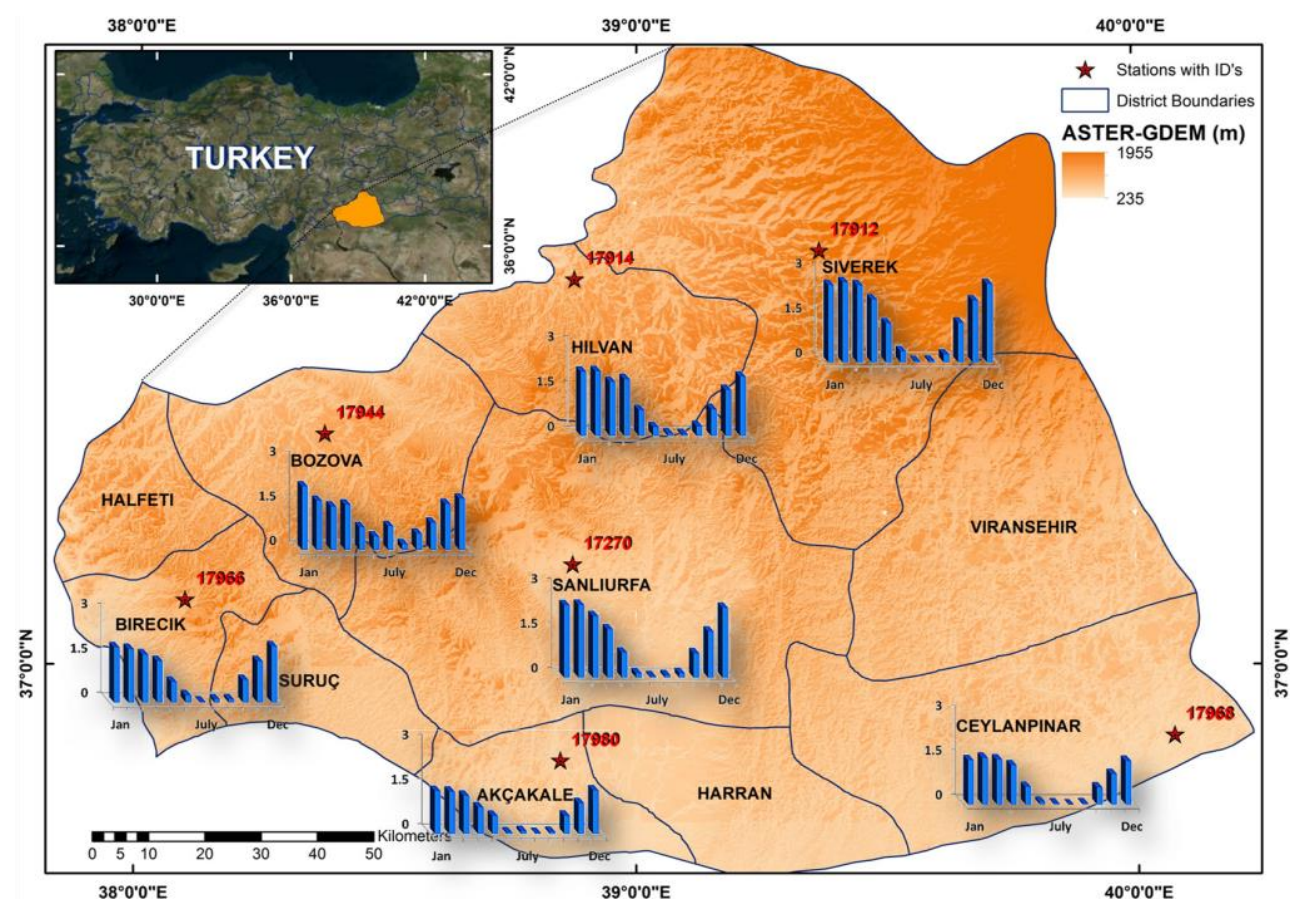

Fig 1. The study region and the locations of the rain gauge stations. The inset graphics represent the monthly mean diurnal rainfall variations of each associated rain gauge stations within the period of 1970 to 2012 .

\section{METHODOLOGY}

GEV distribution is built into the extreme value theory to combine the Gumbel, Frechet, and Weibull distributions, known as the extreme value distribution of type I, II, and III. On the GEV distribution, $x$ is the random variable that only takes continuous real values. The probability density function (PDF) and cumulative distribution function (CDF) of a GEV distribution are defined respectively by equations 1 and 2 .

$f(x: \mu . \sigma . \xi)=\left\{\begin{array}{c}\frac{1}{\sigma}\left[1+\xi\left(\frac{x-\mu}{\sigma}\right)\right]\left(\frac{-1}{\xi}\right)-1 \exp \left\{-\left[1+\xi\left(\frac{x-\mu}{\sigma}\right)\right] \frac{-1}{\xi}\right\}, \xi \neq 0 \\ \frac{1}{\sigma} \exp \left\{-\frac{x-\mu}{\sigma}\right\} \exp \left\{-\exp \left(-\frac{x-\mu}{\sigma}\right)\right\}, \xi=0\end{array}\right.$

$F(x: \mu . \sigma . \xi)=\exp \left\{-\left[1+\xi\left(\frac{x-\mu}{\sigma}\right)\right]^{\frac{-1}{\xi}}\right\}$

where $1+\xi(x-\mu) / \sigma>0$

In a GEV distribution, there are three model parameters: the location parameter $\mu$, the scale a parameter $\sigma$, and the shape parameter $\xi$. Shape parameter $\xi$ determines the behavior of the tail of the distribution and in general, improves the fit to the upper tail (i.e., extremely large values). Distribution type defined with $\xi=0, \xi>0$, and $\xi<0$ and can be likened to the Gumbel, Frechet, and Weibull distribution. In this study, GEV distribution parameters have been estimated by using Maximum
Likelihood Estimation (MLE) at 5\% level of significance. One approach to define extreme precipitation events is to calculate return periods of the event based on the annual maximum daily rainfall series (e.g., Kunkel et. al., 1999). The return period, also called the recurrence interval, refers to the maximum value that is expected to be reached within the period of time $T$ with period $p$, or in other words, in the $T$ and $p$ period, precipitation will reach the maximum value one time (Gilli et al., 2003):

$$
R_{p}^{T}=\left\{\begin{array}{l}
\mu-\frac{\sigma}{\xi}\left\{1-\left[-\ln \left(1-\frac{1}{T}\right)\right]^{-\xi}\right\}, \xi \neq 0 \\
\mu-\sigma \ln \left\{\left(-\ln \left(1-\frac{1}{T}\right)\right)\right\}, \xi=0
\end{array}\right.
$$

Maximum annual and daily rainfalls from TRMM 3B42 dataset were calculated based on the 3-h measurement intervals over the time period from 1998 to 2012. The performance of the GEV distribution have been investigated by $\mathrm{CDF}$ and probability-probability (P-P) plots for all 7 stations (Fig. 2).

To obtain recurrence intervals, first a series of extreme values are obtained from the historical data set. Then a GEV CDF is calculated from this series. This function contains shape, location, and scale parameters that are estimated based on the temporal length and distribution of values contained in the dataset. To fit values one can get the median and then vary $\mu$ until it fits the list of values. To illustrate the model ability to reproduce extremes, the observed time series of annual maximum daily rainfall at each gauge was plotted (43 years), along with their corresponding simulated rainfalls obtained. 


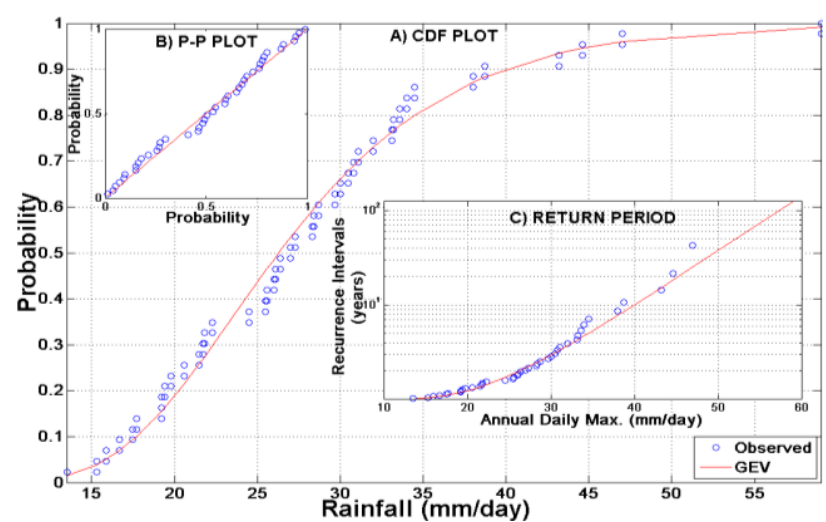

Fig 2. A) CDF, B) P-P and C) Return Period plots of Akcakale rain gauge station within the period from 1970 to 2012 .

The capacity of the model to represent annual maximum daily rainfall for various return periods has been assessed by plotting the observed and the simulated annual maximum daily rainfall. In regional frequency analysis (Hosking and Wallis, 1997), the final and important objective is to determine the robustness of the selected distribution in constructing reasonable and reliable estimation at all sites. The capabilities of the selected regional frequency distribution were further investigated for estimation of design variable quantiles of specific recurrence intervals and described how they vary among the stations and the associated TRMM 3B42 grid cells. Spatiotemporal patterns across the study area and correlations of rainfall events between rain gauges and TRMM 3B42 grid cells through statistical analyses were identified and individual maps were produced.

\section{RESULTS AND DISCUSSION}

In the study, statistical evaluations include the calculation of the $90^{\text {th }}, 95^{\text {th }}, 99^{\text {th }}$ percentiles and the estimation of the recurrence intervals for different years. 15 years of precipitation retrievals from the TRMM satellite were compared with data from 7 surface rain gauge stations for the same time interval.

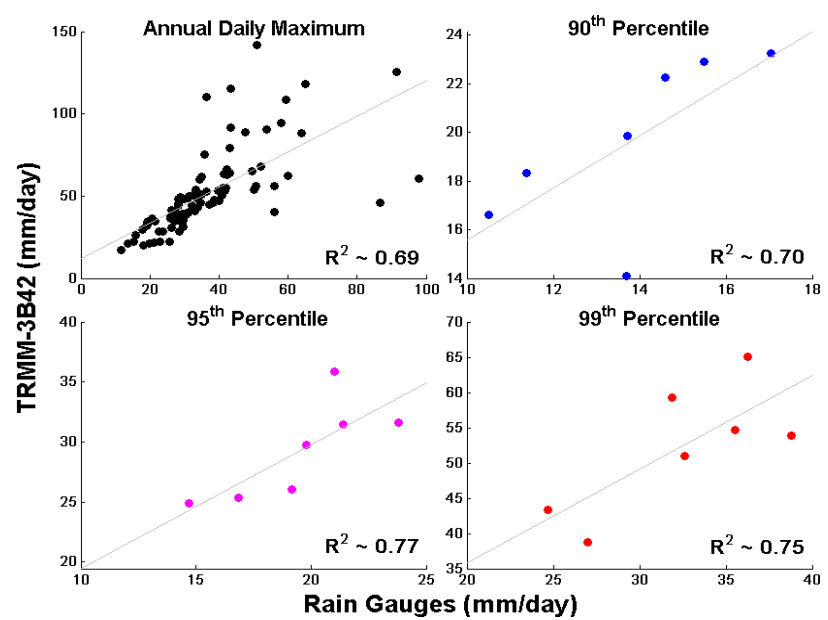

Fig 3. Correlations of the annual daily maximum rainfalls and the $90^{\text {th }}, 95^{\text {th }}, 99^{\text {th }}$ percentiles between rain gauges and TRMM 3B42 grid cells.

Based on the chosen threshold of the percentiles, we determined daily rainfall amounts of extreme events for all rain gauge stations and compared them to the related TRMM grid cells (Fig. 3). In the calculation of percentiles, all days with no precipitation or days with precipitation of less than $0.1 \mathrm{~mm}$ were ignored (i.e., we only considered wet days). Preliminary results indicate that there exist large discrepancies between rain gauge and TRMM data at mean rainfall values; however, least squares fits indicate some high and quite linear correlation for the $90^{\text {th }}, 95^{\text {th }}, 99^{\text {th }}$ percentiles $\left(r^{2}=0.70,0.77\right.$ and 0.75 respectively) and the annual maximum daily amount of precipitation $\left(\mathrm{r}^{2}=0.69\right)$. The regional frequency relationship has been developed by fitting GEV distribution, which comprises the three limiting types as special cases for specific values of its shape parameter. For the comparison of the return periods, the largest daily value in each of $n$ years, known as block maximum series, was chosen.

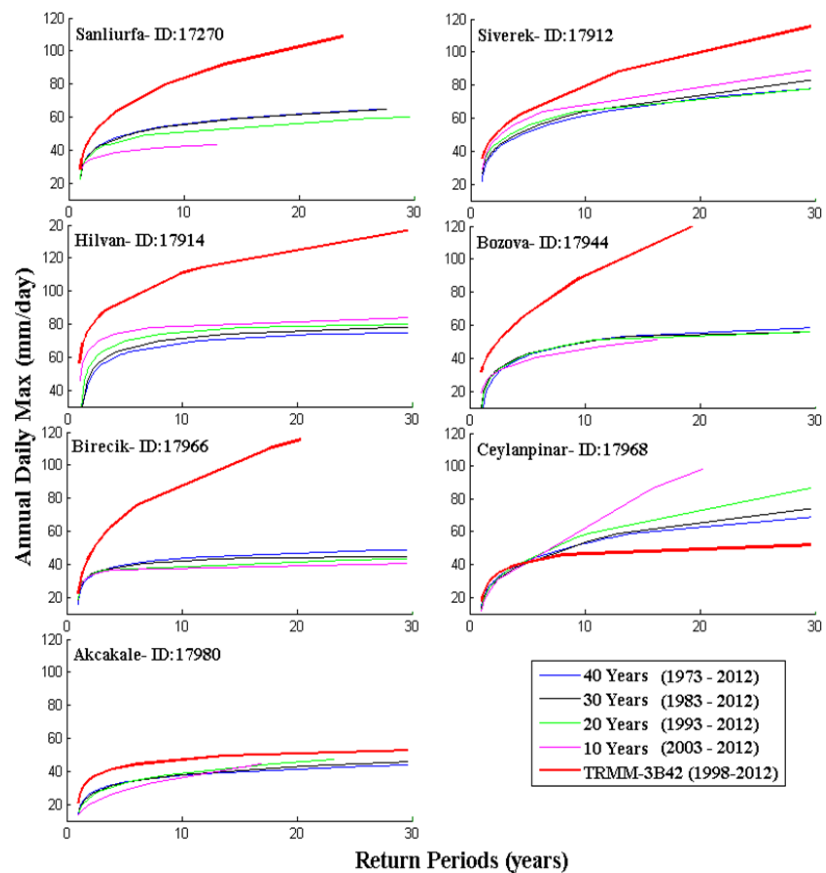

Fig 4. Return Periods of rain gauges and TRMM 3B42 data for different timescales.

The annual maximum daily rainfall values associated with different return periods have been determined within the period of 1970 - 2012 (Fig. 4). Recurrence intervals derived from raingauge measurements for 10 to 40 -year periods yielded similar results. Although rainfalls from each TRMM 3B42 grid cells are generally overestimated compared against rain gauge data, data compare well for stations which were located at approximately the mean elevation of the related TRMM 3B42 grid cell. The spatiotemporal pattern analysis of the computed extreme statistics is conducted using geographic information systems. The comparison of the spatial distributions for the 20year return period of extreme events is shown in Figure 5. Values indicate maximum daily rainfall associated with 20 -year recurrence intervals. The spatial gradient is based on an inversedistance-weighted (IDW) interpolation algorithm and applied to 15-years of TRMM data. In Figure 6, the spatial distributions of the GEV shape parameter of rain gauges and TRMM 3B42 states that the increase in the shape parameter explains the differences between the changes in large quantiles of the daily precipitation extremes. Large positive shape parameter estimates can be a consequence of a few extremely high rainfall events and describes situations where extremes have an upper bound. Although there were similar results in shape values between the TRMM and rain gauge data in the center of the study area, some significant differences were encountered in the north-western and the south-eastern part of the study area. 


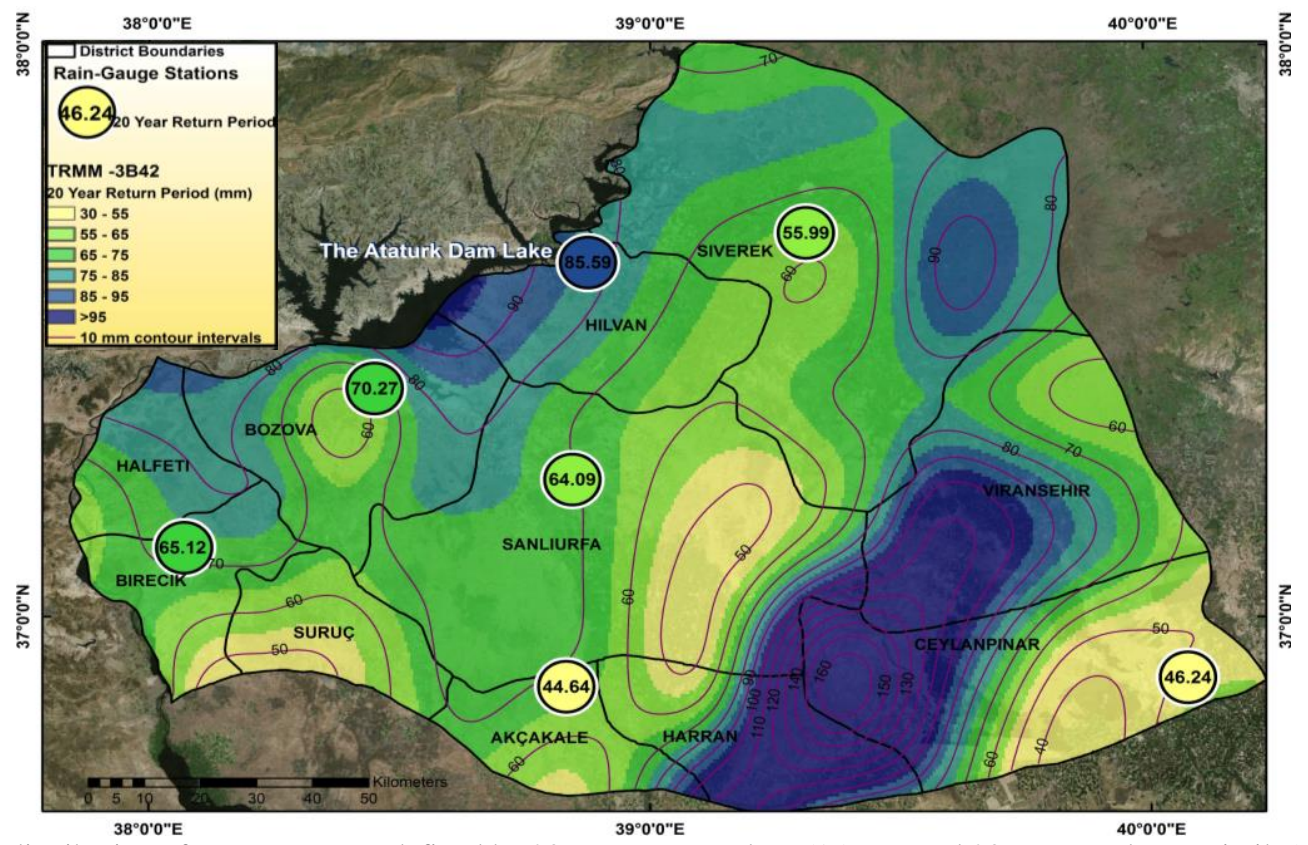

Fig 5. Spatial distribution of extreme events defined by 20-year return values (15-year and 20-year results are similar) of the annual maximum daily rainfall using the GEV distribution. Color background shows results from Inverse Distance Weighted (IDW) and is based on TRMM values. Circles indicate gauge-based recurrence intervals within a 20 -year period.

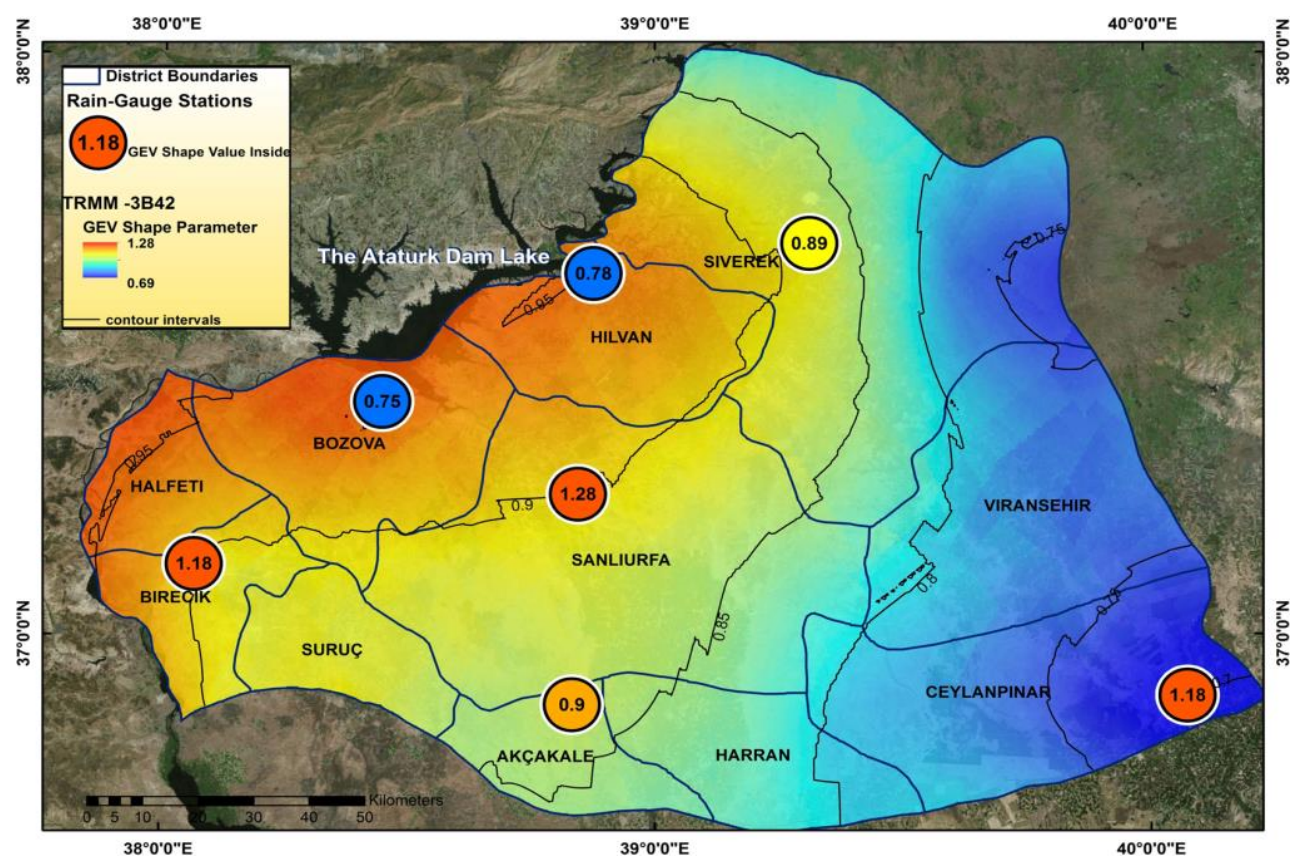

Fig 6. Spatial distribution of the GEV shape parameter for rain gauges (circles) and TRMM 3B42 for the period of 1998 to 2012.

\section{CONCLUSIONS}

Understanding the study area and the hydro-meteorological data is important because it reflects weather systems and the characteristics of its meteorological and hydrological cycle. Considering the sensitivity of agricultural production to climate factors, adoption strategies must be carefully developed based on knowledge and observation. The purpose of the present study is the analysis of spatiotemporal patterns of extreme precipitation events by comparing the TRMM 3B42 product versus rain gauge network. Satellite rainfall estimates are being used widely in place of gauge observations or to supplement gauge observations. Our limited analysis and comparions indicate a relatively weak correlation of mean rainfall amounts between rain gauge and TRMM 3B42 data. Rainfall amounts between the two datasets vary significantly. However, some statistical and spatial results are remarkable well correlated. We conclude that TRMM 3B42 can be used to assess first-order rainfall statistics and recurrence intervals.

Acknowledgments. The data used in this study were acquired as part of the Tropical Rainfall Measuring Mission (TRMM) sponsored by the Japan National Space Development Agency (NASDA) and the US National Aeronautics and Space Administration (NASA). The rain gauge data were graciously provided by Turkish State Meteorological Service. This work was supported with a grant from The Scientific and Technological Research Council of Turkey - 2214 International Doctoral Research Fellowship Programme. 


\section{REFERENCES}

Adler, R.F., and co-authors., 2001. Intercomparison of global precipitation products: the Third Precipitation Intercomparison Project. Bulletin of the Amer. Meteo. Soc., 82, pp. 1377-1396.

Adler, R.F., and co-authors., 2003. Status of TRMM monthly estimates of tropical precipitation, in Cloud Systems, Hurricanes, and the TRMM, Met. Soc. Monogr., 29, 223-234.

Boers, N., and co-authors., 2013. Complex networks identify spatial patterns of extreme rainfall events of the South American Monsoon System, Geophys. Res. Lett., 40, 10.1002/grl.50681.

Bookhagen, B., 2010. Appearance of extreme monsoonal rainfall events and their impact on erosion in the Himalaya, Geomatics, Natural Hazards Risk, 1, 1, pp. 37-50.

Bookhagen, B., and Burbank, D.W., 2010. Towards a complete Himalayan hydrological budget: The spatiotemporal distribution of snow melt and rainfall and their impact on river discharge, $J$. Geophys. Research-Earth Surface, doi:10.1029/2009jf001426.

Bookhagen, B., Thiede, R.C., Strecker. M.R., 2005. Abnormal Monsoon years and their control on erosion and sediment flux in the high, arid northwest Himalaya, Earth and Planetary Science Letters, 231, 131-146.

Bookhagen, B. and Strecker, M.R. (2008): Orographic barriers, high-resolution TRMM rainfall and relief variations along the eastern Andes, Geophysical Research Letters, 35, L06403.

Ebert, E.E., Janowiak, J.E., and Kidd, C., 2007. Comparison of near-realtime precipitation estimates from satellite observations and numerical models, Bull. Am. Meteorol. Soc., 88, 47-64.

Embrechts P., Resnick, S., and Samorodnitsky, G., 1999. Extreme value theory as a risk management tool, North American Actuarial Journal, 3, 30-41.

Fekete, B.M., Vorosmarty, C.J., Roads, J.O., and Willmott C.J., 2003. Uncertainties in precipitation and their impact on runoff estimates. J. Climate, 17, 294-304.

Gebremichael, M., et al., 2005 A detailed evaluation of GPCP one-degree daily rainfall estimates over the Mississippi River Basin. Journal of Applied Meteorology, 44, pp. 665-681.

Gilli, M.,and Kellezi, E., 2003. An Application of Extreme Value Theory for Measuring Risk (Switzerland: Geneva).

Gottschalck, J., Meng, J., Rodell, M., and Houser, P., 2005. Analysis of multiple precipitation products and preliminary assessment of their impact on Global Land Data Assimilation System land surface states. J. Hydrometeor., 6, 573-598.

Hosking, J.R.M., and Wallis, J.R., 1997. Regional Frequency Analysis, An Approach Based on Lmoments, Cambr. Univ. Pr.

Huffman, G.J., et al., 2007. The TRMM Multisatellite Precipitation Analysis: quasi-global, multiyear, combinedsensor precipitation estimates at fine scales. J. Hydromet, 8, 38-55.

Jenkinson, A.F., 1955. The frequency distribution of the annual maximum (or minimum) values of meteorological elements. Quarterly J.of the Royal Meteorological Society, 87, 158-171.
Koo, M.S., Hong, S.Y., and Kim, J., 2009. An evaluation of the TRMM Multi-Satellite Precipitation Analysis (TMPA) data over South Korea. Asia-Pacific J. of Atmos. Sci., 45, 265-282.

Krajewski, W.F., and co-authors., 2000. Initial validation of the Global Precipitation Climatology Project monthly rainfall over the US. J. App. Met., 39, 1071-1086.

Kummerow, C., and co-authors., 2000. The status of the TRMM after two years in orbit. J. Appl. Met. , 39, 1965-1982.

Kunkel, K. E., Andsager, K., and Easterling D. R., 1999. Longterm trends in extreme precipitation events over the conterminous US and Canada. J. Climate, 12, 2515-2527.

Kunkel, K.E., and co-authors., 1999. Temporal fluctuations in weather and climate extremes that cause economic and human health impacts, B. Am. Meteor. Soc., 80:1077-1098.

Nicholson, S. E., et al., 2003. Validation of TRMM and other rainfall estimates with a high-density gauge dataset for West Africa. Part I, J. Appl. Meteorol., 42, 1337-1354.

Okamoto, K., 2003. A short history of the TRMM precipitation radar, in Cloud Systems, Hurricanes, and the Tropical Rainfall Measuring Mission (TRMM), Meteorol. Soc. Monogr., vol. 29, pp. 187-195, Am. Meteorol. Soc., Boston, Mass.

Ozcan, O., Bookhagen, B., and Musaoglu, N., 2012. Impact of the Ataturk Dam Lake on Agro-Meteorological Aspects of the Southeastern Anatolia Region Using Remote Sensing and GIS Analysis. XXII. ISPRS Congress, 25 Aug.-1Sept. Melbourne.

Sapiano, M. R. P., and Arkin, P. A., 2009. An intercomparison and validation of high resolution satellite precipitation estimates with 3-hourly gauge data. J. Hydrometeorol, 10, pp. 149-166.

Simpson, J., Alder, R. F., and North, G. R., 1988. A proposed Tropical Rainfall Measuring Mission (TRMM) satellite. Bull. Amer. Meteor. Soc., 69, 278-295.

Wilheit, T., 2003. The TRMM measuring concept, in Cloud Systems, Hurricanes, and the TRMM, Meteorol. Soc. Monogr., vol. 29, pp. 197-200, Am. Meteorol. Soc., Boston, Mass.

Wolff, D. B., and co-authors, 2005. Ground validation for the TRMM. J. Atmos. Oceanic Technol., 22, 365-380.

Wulf, H., Bookhagen, B., and Scherler, D., 2012. Climatic and Geologic Controls on Suspended Sediment Flux in the Sutlej River Valley, Western Himalaya. HESS, 16, 2193 - 2217.

Wulf, H., Bookhagen, B., and Scherler, D., 2010. Seasonal Precipitation Gradients and their Impacts on Fluvial Sediment Flux in the Northwest Himalaya. Geomorphology, 118, 13-21.

Xie, P., and Arkin, P. A., 1995. An intercomparison of gauge observations and satellite estimates of monthly precipitation. Journal of Applied Meteorology, 34, pp. 1143-1160.

Zscheischler, J., Mahecha, D. M., Harmeling, S., Reichstein, M., 2013. Detection and attribution of large spatiotemporal extreme events in Earth observation data. Eco. Inf., 15, 66-73. 